\title{
Evaluation of traumatic ocular injuries using high resolution ultrasound
}

\author{
Rushvik Amin ${ }^{1}$, Sushil Kachewar ${ }^{2}$, Dilip Lakhkar ${ }^{3}$ \\ ${ }^{1}$ Resident, ${ }^{2,3}$ Professor, Department of Radio-diagnosis, VVPF's Medical College and Hospital, Ahmednagar, Maharashtra, INDIA \\ Email: dr.rushvikamin@gmail.com
}

\begin{abstract}
$\underline{\text { Abstract }}$
Background: Patients with ocular trauma present with blunt or penetrating injuries and appropriate, timely management is crucial. Radiological diagnosis using ultrasound serves as a key role to Ophthalmologist for guiding the management. Method: 40 patients with ocular injuries who underwent high resolution ultrasound in a tertiary care setup were included in the study. Results: Among evaluated 40 patients 29 were male (72.5\%) and 10 cases belonged to the age group of 21 to 30 years $(25 \%)$. Among all the findings Vitreous hemorrhage was the commonest finding $(40 \%)$ followed by cataract (30\%). Other findings were retinal, choroidal detachment, foreign body and pre-orbital swelling. Conclusion: High resolution ultrasound serves as a cheap, easily available, portable, non-radiating modality to evaluate patients presenting with history of ocular injuries. Static and dynamic study is performed to accurately evaluate both intra and extra orbital structures to reach the diagnosis which helps the Ophthalmologist in management of patient.
\end{abstract}

*Address for Correspondence:

Dr. Sushil Kachewar, Professor, Department of Radio-diagnosis, VVPF's Medical College and Hospital, Ahmednagar, Maharashtra, INDIA

Email: dr.rushvikamin@gmail.com

Received Date: 10/09/2019 Revised Date: 13/10/2019 Accepted Date: 02/11/2019

DOI: https://doi.org/10.26611/10151513

This work is licensed under a Creative Commons Attribution-NonCommercial 4.0 International License. $(\boldsymbol{\infty})$ ) EY-NC

\begin{tabular}{|l|l|}
\hline \multicolumn{2}{|c|}{ Access this article online } \\
\hline Quick Response Code: & Website: \\
\hline & www.medpulse.in \\
\hline
\end{tabular}

\section{INTRODUCTION}

Worldwide approximately 1.6 million people are blinded due to trauma and it is also the most common cause of unilateral blindness. ${ }^{1}$ Ocular injuries can occur by multiple ways like physical, chemical contact. All ocular injury patient are always considered an emergency. At several occasions ophthalmologists have found it difficult to completely assess the status of the traumatic eye after opacification of cornea, lens and vitreous. International Society for Ocular Trauma Classification distinguishes between open and closed globe trauma. Open globe injury is due to full thickness laceration of corneo-scleral wall which may result from blunt or penetrating trauma whereas closed globe injury is caused by blunt trauma. ${ }^{1}$ Multiple radiological modalities are available for the ocular assessment including- conventional radiography, high-resolution Ultrasound (HRU), Computed Tomography (CT), Magnetic Resonance Imaging (MRI). Out of all these modalities high resolution ultrasound can be used to guide and aid the management of traumatic eye. As traumatic ocular injury is an emergency ultrasound serves as a quick inexpensive dynamic study and does not require special patient preparation and is neither time consuming nor requires software processing to generate images. Aim and objective of this study was to evaluate varied ocular conditions following trauma using high resolution ultrasound.

Indication: To assess the eye/globe following trauma using high resolution ultrasound and evaluate the varied spectrum of lesions.

\section{METHODS AND MATERIAL}

Patients who presented to Ophthalmology department with traumatic injury to eye were clinically evaluated. Along with alleged history of trauma to the eye they also had complaints of pain and redness of eye, diminution of vision and swelling around the eye. All these patients were further followed-up in the Department of RadioDiagnosis for further evaluation. They were assessed on MINDRAY ultrasound machine DC-7 model on B scale and color Doppler mode. 40 patients who presented with ocular trauma were included in the study. 
Inclusion criteria: Patients who presented with ocular trauma. Patients willing to participate in the study.

Exclusion criteria: Patients not willing to participate in the study. Standard imaging protocols- Patients were lying supine on the examination table. Eye-lids were wiped using normal saline swab. Under all aseptic precaution using clean probe and jelly. Static images were examined on B-scan and color Doppler mode. Dynamic examination on B-scan and color Doppler mode. After complete evaluation eye-lids were cleaned using sterile cotton swab.

Ethical Approval was taken from Institutional ethical committee.

\section{RESULTS}

\begin{tabular}{cc}
\multicolumn{2}{c}{ Table 1: Genderwise distribution } \\
\cline { 2 - 2 } Gender & No. of cases (Percentage) \\
\hline Male & $29(72.5 \%)$ \\
Female & $11(27.5 \%)$ \\
\hline Total & $40(100 \%)$ \\
\hline
\end{tabular}

Table 2: Age Distribution

\begin{tabular}{|c|c|c|}
\hline & \\
\hline Age Group (years) & No. of cases (Percentage) & \\
\hline $0-10$ & $1(2.5 \%)$ & \\
\hline $11-20$ & $6(15 \%)$ & \\
\hline $21-30$ & $10(25 \%)$ & \\
\hline $31-40$ & $6(15 \%)$ & \\
\hline $41-50$ & $5(12.5 \%)$ & \\
\hline $51-60$ & $4(10 \%)$ & \\
\hline $61-70$ & $5(12.5 \%)$ & \\
\hline $71-80$ & $3(7.5 \%)$ & \\
\hline Total & $40(100 \%)$ & \\
\hline \multicolumn{3}{|c|}{ Table 3: Ocular pathologies } \\
\hline Lesions & & No. of cases (Percentage) \\
\hline \multicolumn{2}{|c|}{$\begin{array}{c}\text { Cataract } \\
\text { Cataract }+ \text { Vitreous hemorrhage }\end{array}$} & $6(15 \%)$ \\
\hline \multicolumn{2}{|c|}{ Cataract + Vitreous hemorrhage } & $4(10 \%)$ \\
\hline \multicolumn{2}{|c|}{ Cataract + Retinal Detachment } & $2(5 \%)$ \\
\hline \multicolumn{2}{|c|}{ Vitreous hemorrhage } & $6(15 \%)$ \\
\hline \multicolumn{2}{|l|}{ Retinal Detachment } & $3(7.5 \%)$ \\
\hline \multicolumn{2}{|c|}{ Vitreous hemorrhage + Retinal Detachment } & $4(10 \%)$ \\
\hline \multicolumn{2}{|c|}{ Vitreous hemorrhage + Retinal Detachment + Choroid Detachment } & $2(5 \%)$ \\
\hline \multicolumn{2}{|l|}{ Subluxation / Dislocation } & $5(12.5 \%)$ \\
\hline \multicolumn{2}{|c|}{ Foreign body } & $2(5 \%)$ \\
\hline \multicolumn{2}{|l|}{ Pre-orbital swelling } & $3(7.5 \%)$ \\
\hline \multicolumn{2}{|l|}{ No abnormality detected } & $3(7.5 \%)$ \\
\hline \multicolumn{2}{|l|}{ Total } & $40(100 \%)$ \\
\hline
\end{tabular}

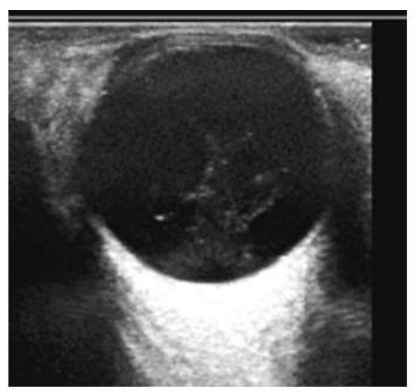

Image 1

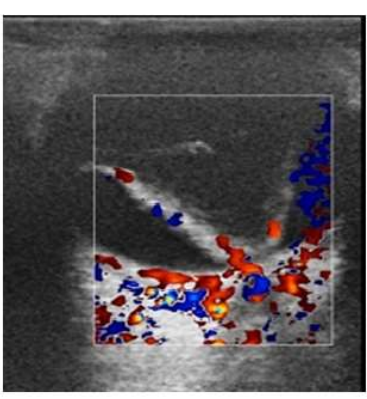

Image 2
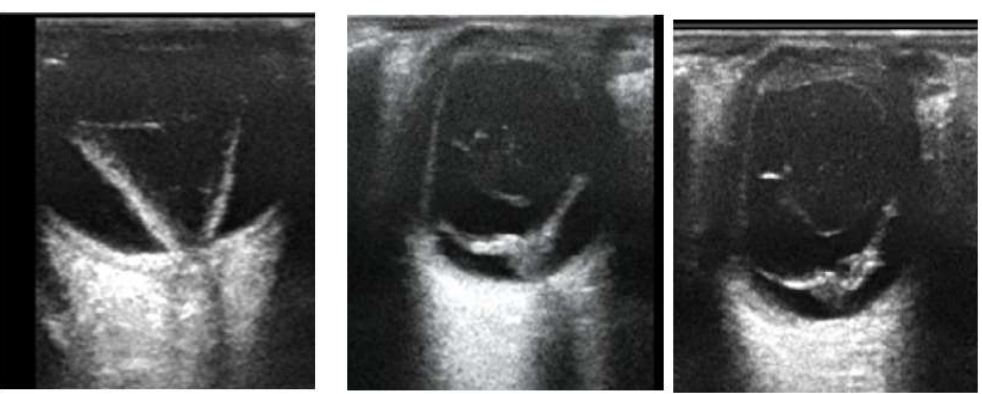

Image 3 


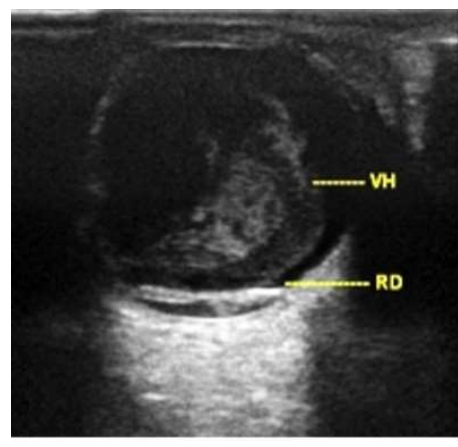

Image 4

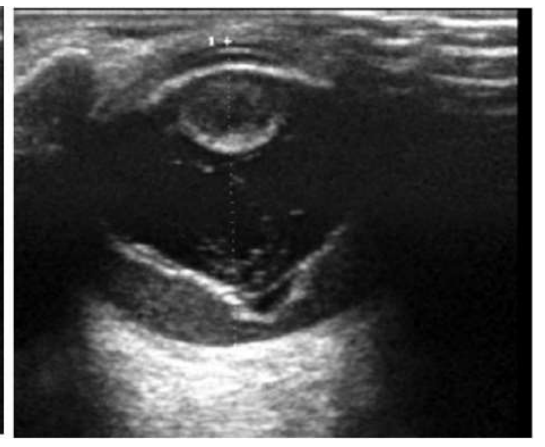

Image 5

Image 1: 62 years old male came with history of blunt trauma showing vitreous hemorrhage - dense echos with membranes; Image 2: 28years old female showing retinal detachment - seen as V Shaped thick membrane attached posteriorly to the optic disc; Image 3: 48 years male had vitreous, retinal and choroidal detachments. Vitreous detachment is seen as freely mobile membrane with movement of eye ball. Retinal detachment seen as $\mathrm{V}$ shaped membrane attached posteriorly at optic disc. Choroidal detachment seen as temporal and nasal side membranes; Image 4: 28 years old male patient showing vitreous hemorrhage with retinal detachment. retinal detachment seen as $V$ shaped thick membrane attached posteriorly to the optic disc and vitreous hemorrhage - dense echos with membranes; Image 5: 42 year old patient showing retinal detachment seen as $\mathrm{V}$ shaped thick membrane attached posteriorly to the optic disc with sub-retinal collection with cataract seen as echogenic intra-substance in the lens.

\section{DISCUSSION}

In our study evaluating traumatic eye using high resolution ultrasound we observed that out of 40 patients $29(72.5 \%)$ were male and $11(27.5 \%)$ were female $(M: F=$ 2.63:1). Epidemiology of ocular trauma (book by Shukla) states, that in India eye injuries are found more in males $(81 \%)$. It also mentions that in sedentary workers, farmers, laborers and industrial worker this percentage goes higher (91\%). ${ }^{2}$ In another study by EzeKC et al it was observed that $83.58 \%$ were males and $16.42 \%$ were females. ${ }^{3}$ Dastevska-Djosevska E study shows $85.2 \%$ were males and $14.8 \%$ were females. ${ }^{4}$ Most of the patients belonged to the age group 21 to 30 years $(25 \%)$ followed by 11 to 20 years and 31 to 40 years $(15 \%$ each).Study conducted by Daksha Patel shows bimodal age wise distribution one peaks in the age group of 5 to 25 years and the other in 70 years and above, however demographic pattern (age / gender) varies with environment and cause of injury. ${ }^{5}$ Another study by EzeKC et al shows mean age for ocular trauma as 30.8 years. 3 Vitreous hemorrhage was the most common finding observed in 16 patients $(40 \%)$ followed by cataract in 12 patients (30\%). In study by Elshafie MA et al commonest finding was vitreous haemorrhage and retinal detachment $21 \%$ followed by traumatic cataract with iridodialysis $17.9 \%$ cases and vitreous hemorrhage in $15.8 \%$ cases. $^{6}$ Another study by EzeKC et al shows retinal detachment $(26.87 \%)$, vitreous haemorrhage $(25.37 \%)$, traumatic cataract $(19.40 \%)$, ruptured globe $(8.96 \%)$ and posterior dislocation of the lens $(8.96 \%)$ was the spectrum of abnormal sonographic findings. ${ }^{3}$ Study by Dastevska-Djosevska E showed vitreous hemorrhage was the most common ultrasonographically detected pathology. 4

\section{Vitreous:}

In our study vitreous hemorrhage was the most common finding in 16 patients $(40 \%)$. It was seen as a primary finding in 6 patients $(15 \%)$ and associated with other findings like cataract, retinal and choroid detachments in 10 patients $(25 \%)$.

Fresh mild hemorrhage is seen as a dots and short lines and more echogenic on dense hemorrhage. In diffusely scattered hemorrhage multiple internal echos are seen throughout the vitreous. Some degree of posterior vitreous detachment may accompany vitreous hemorrhage. Detached vitreous is usually smooth but may be echogenic and thick posteriorly, when blood is layered on it. On kinetic ultrasound it shows undulating after movement which helps in distinguishing from less mobile retinal and choroidal detachments. ${ }^{7} \mathrm{~B}$ scan helps in detecting the volume, extent and degree of organization of vitreous hemorrhage. ${ }^{8}$

\section{Lens:}

In our study traumatic cataract was the second most common finding 12 patient (30\%). It was found as an isolated finding in 6 patients $(15 \%)$ and associated with vitreous hemorrhage and retinal detachment in 6 patients (15\%). On ultrasound assessment position, low internal reflectivity and integrity should be assessed. Cataractous lens shows high internal reflective echogenicity. ${ }^{10}$ Traumatic cataract can develop hours after trauma and shows echogenic posterior capsule. ${ }^{9}$ Lens subluxation is defined as partial disruption of zonular fibers such that lens is no longer held securely but remains in the pupillary aperture. Lens dislocation is defined as complete disruption of zonular fibers and displacement of lens from pupillary aperture. ${ }^{10}$ Vitreoretinal abnormalities 
are usually associated with traumatic cataract, in our study 6 patients $(15 \%)$ shows associated vitreoretinal pathology. Study by Kaskalogu M has reported 20 to $30 \%$ incidence of vitreoretinal abnormality with traumatic cataract. ${ }^{11}$

\section{Retina and Choroid:}

In the setting of opaque media due to trauma, retinal evaluation by ultrasound is very useful in adding important value to diagnosis and further management. In our study 11 patient had retinal detachment $(27.5 \%)$ out of which 3 patients had only retinal detachment $(7.5 \%)$ and others had associated multiple findings including cataract, vitreous hemorrhage and choroid detachment together comprising 8 patients (20\%). Usually rhegmatogenous and tractional type of retinal detachment are common with traumatic ocular injury. ${ }^{10}$ Rhegmatogenous type of retinal detachment are caused by hole or tear in the retina causing fluid to accumulate behind the retina with retinal detachment. Tractional type of retinal detachment have scar tissue which grows on the retina causing pulling of retina with retinal detachment. Retinal detachment appears as echogenic freely movable membrane with attachment of retina at optic nerve head posteriorly and ora serrata anteriorly forming a funnel shape. Choroidal detachment presents as smooth, thick dome shaped membrane on the nasal and temporal aspect with little after movement on kinetic evaluation. ${ }^{3,4}$ In 2 patients $(5 \%)$ foreign body was noted in the anterior chamber. Foreign body usually appears as echogenic material with posterior acoustic shadowing. In 3 patients $(7.5 \%)$ only pre-orbital swelling was noted without any other abnormal ocular anatomic In 3 patients $(7.5 \%)$ ultrasound did not showed any abnormality. In study by Eze $\mathrm{KC}$ et al shows $67.16 \%$ were having some anatomical pathology in one or both eye and $32.84 \%$ were normal. ${ }^{3}$

\section{CONCLUSION}

$\mathrm{B}$ scan is safe, cost effective, noninvasive and a rapid investigation in emergency setting of ocular trauma. It is reliable and helps in screening intra and extra ocular structures and gives information about lens, retina, vitreous, choroid and sclera. It also helps in evaluating posterior segment and helps in preoperative planning. Patients presenting with penetrating ocular injuries causing globe perforation could not be further evaluated on ultrasound examination because of high risk of herniation of eye ball content.

\section{REFERENCES}

1. Ozougwu NS, Adeyekun AA, Ese-Onakewhor NJ, EfeAluta EE. Sonographic features of patients with ocular trauma at the University of Benin Teaching Hospital, Benin-City. Annals of Health Research. 2018; 4(2): 147181.

2. Shukla B. Epidemiology of ocular trauma. Jaypee Brothers; 2002.

3. Eze KC, Enock ME, Eluehike SU. Ultrasonic evaluation of orbito-ocular trauma in Benin-City, Nigeria. Niger Postgrad Med J. 2009; Sep;16(3):198-202

4. Dastevska-Djosevska E. Ultrasonography in ocular trauma. Pril (Makedon Akad Nauk Umet Odd Med Nauki). 2013;34(2):105-13

5. Patel D. Eye injuries: improving our practice. Community Eye Health. 2015;28(91):41-43.

6. Elshafie M A, Abouelkheir H Y, Othman M M, Elhefny E M. Ultrasonic evaluation of eyes with blunt trauma. Journal of The Egyptian Opthalmological Society.2018; 111(1): 20-24.

7. Chugh J P, Susheel, Verma M. Role of ultrasonography in ocular trauma. Indian Journal Of Radiology And Imaging 2001;11(2):75-93

8. Mundt GH, Hughes WF. Ultrasonics in ocular diagnosis. Am J Ophthalmol. 1956; 41: 488-98.

9. Baum G, Greenwood I. The application of ultrasonic locating technique to ophthalmology. Arch Ophthalmol. 1958; 60: 263-79.

10. Recchia F M, Sternberg P. Surgery for Ocular Trauma: Principles and Techniques of Treatment of Retina. 2013; 5(3):1852-1875

11. Kaskalogu M. US findings in eyes with traumatic cataracts. American Journal of Ophthalmol. 1985; 9: 496.

12. Aironi VD, Gandage SG. Pictorial essay: B-scan ultrasonography in ocular abnormalities. Indian J Radiol Imaging. 2009 May; 19(2): 109-115.

13. Bronson N R, Turner F T. A simple B-scan ultrasonoscope. Arch ophthalmol. 1973; 90: 237-238.

\section{Source of Support: None Declared Conflict of Interest: None Declared}

Policy for Articles with Open Access:

Authors who publish with MedPulse International Journal of Anesthesiology (Print ISSN:2579-0900) (Online ISSN: 2636-4654) agree to the following terms: Authors retain copyright and grant the journal right of first publication with the work simultaneously licensed under a Creative Commons Attribution License that allows others to share the work with an acknowledgement of the work's authorship and initial publication in this journal.

Authors are permitted and encouraged to post links to their work online (e.g., in institutional repositories or on their website) prior to and during the submission process, as it can lead to productive exchanges, as well as earlier and greater citation of published work. 